كلمة التحرير

\title{
المعرفة في "إسلامية المعرفة"
}

تسود لغة النخب العربية والإسلامية -هذه الأيام، وفي ميادين الفكر والثقافة- مفردات وعبارات تحلّي عناوين البحوث والمقالات والمناهج البحثية. ومن أهم هذه المفردات لفظة "المعرفة" وما يتعلق بها من "قضايا معرفية" و "مناهج معرفية" و"تحليل معريف" و "رؤية معرفية" وأمثالها. ويبدو أن لفظ المعرفة ومشتقاته ومرادفاته قد اكتسب موقع التقدير في سائر اللغات البشرية، منذ وقت مبكر من التاريخ. وعندما أصبحت الفلسفة صنعة الفئة المختارة المتميزة من العلماء والحكماء بقيت "نظرية المعرفة" في قلب التفكير والممارسة الفلسفية. وفي اللغة يرد الفعل عرف يعرف عرفاناً ومعرفة، ومنه العَرف والعُرف والمعرفة والتعارف، ويفيد ذلك ما يدركه الإنسان ويثبت معناه في نفسه بصورة تطمئن به وتسكن إليه. وما لا يتم إدراكه ولا يثبت في النفس روتر فإنها تنكره وتتوحش منه،، وتنبو عنه. فالمعرفة حالة نفسية يجدها الإنسان من نفسه حين يجصل الإدراك، وهي بالتالي فعل عقلي ينتج عن تفاعل الذات العارفة بالموضوع المعروف.

ورغم ما ذهب إليه كثير من القدماء والمحدثين من المسلمين وغيرهم، من تمييز بين معنى المعرفة ومعنى العلم، فإن هين المفهومين يتفقان في المعنى العام. فقد فسَّر أهل اللغة المعرفة بالعلم والعلم بالمعرفة، كما أكدّ ذلك ابن حزم في الفصل في الملل والأهواء والنحل، حين بيّن أن العلم والمعرفة اسمان يقعان على معنى واحد. وإن فرّقوا بينهما فقد أبقوا على المعنى العام المشترك، وجعلوا أحد اللفظين أخصّ من الآخر، كما فعل الحسن العسكري في "الفروق اللغوية" حيث جعل المعرفة أخصّ من العلم؛ فكل معرفة علم وليس كل علم معرفة؛ أي أن العلم أشمل من المعرفة باعتبار أن العلم صفة الله سبحانه ولإنسان، أما المعرفة فهي صفة للإنسان فحسب، فيقال: الله عالم، ولا يقال: الله عارف. وهكذا فإن المعنى المشترك بين العلم والمعرفة أهما ميزة مشتركة ميزة مشتركة أساسية للإنسان تتضمن علاقة بين العالم والمعلوم، أو بين الذات العارفة وبين الموضوع 
المعروف؛ أي أن لكلٍ منهما بعداً ذاتياً يتبطُ بالإدراك البشري في العقل والقلب، وبعداً موضوعياً يتحقق

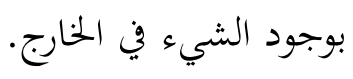

وقد جرت عادة معظم علماء المسلمين أن يبدأوا كتبهم ورسائلهم بفصل عن العلم وفضله وفضل

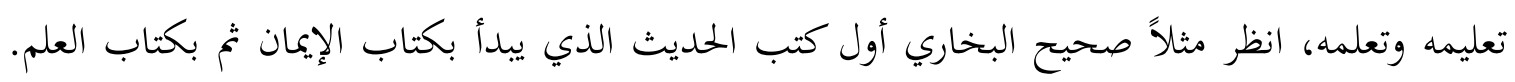

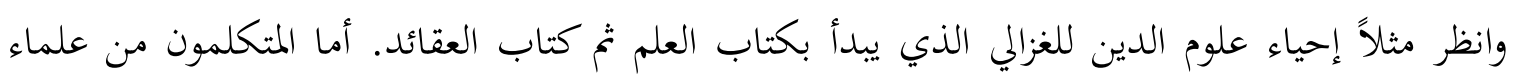
المسلمين فهم يتوسعون في ذلك ويضيفون كلاماً عن حقيقة العلم وأقسامه ومراته. ويأتي هذا الاهتمام باعتبار ذلك تمهيداً أساسياً لقضايا الاعتقاد الإسلامي، وتقديماً ضرورياً لدراسة العقيدة الإسلامية. وإذا كان لفظ العلم في التراث الإسلامي قد اكتسب خاصية المظلة العامة لجممل المعارف الإنسانية، نقد انحصر اللفظ الذي يقابله في اللغات الأوروبية المعاصرة في مجال محدد من المعارف المتعلقة بالكون

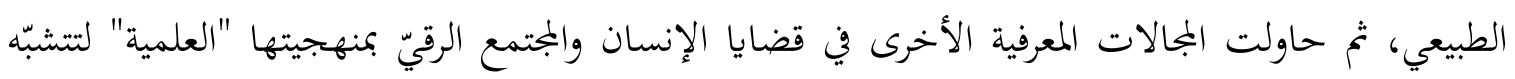

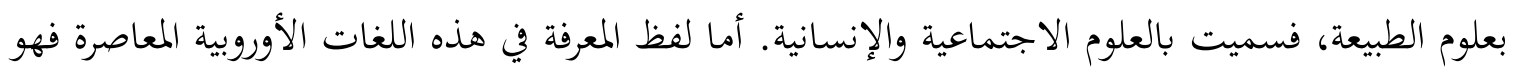
اللفظ العام الذي يشمل معارف الإنسان في الججالات المختلفة؛ الطبيعية والاجتماعية والإنسانية وغيرها.

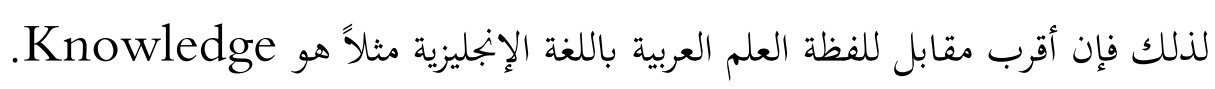
ونشعر بشيء من الأنس والطمأنينة حين نلجأ إلى المصطلح القرآني ودلالاته؛ فنجد أن العلم والمعرفة يتداخلان في كثير من الدلالات، ويشترك معهما كمثير من الألفاظ الأخرى في شيء من هذه الدلالات التات مثل

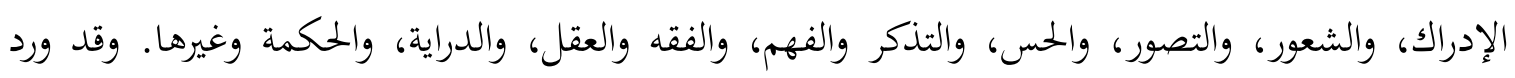

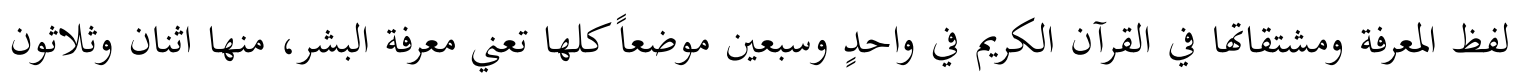

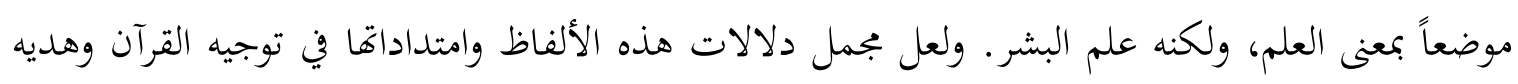
يكفي لبناء نظرية متكاملة في المعرفة.

فمن حيث طبعة المعرفة، ييين القرآن الكريع أن المعرفة كسبية تكتسب بالتفكير والثفكير والفته

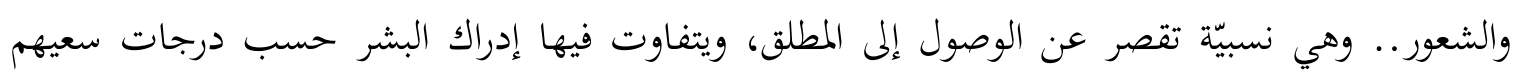


وكسبهم وما يتفضل به الله عليهم. وهي متفاوتة في مستوياتا فمنها ما يقتصر على الاتصال الحسي ومنها ما ينتج عن التجريد العقلي ومنها ما يكون أثراً للعرفان القلبي.

ومن حيث مصادرها، يبين القرآن الكريم أن الله سبحانه هو الذي يهدي الإنسان إلى اكتسابها من مصدرين، تدبر المنلق في هذا الكون المنظور وتدبر الوحي في الكتاب المسطور. ومن حيث أدواتا، يبين القرآن ضرورة توظيف أدوات الحس البشر للاتصال بالأشياء والأحداث والظواهر وتوظيف العقل البشري في تكوين الدلالات والوعي بالمعاني.

ومن حيث غاياتا، يبين القرآن الكريم أن خلف الإنسان ومن ثم توجيه علمه ومعرفته يستهدف عبادة الله سبحانه بالقيام بأمانة الاستخلاف، وحمل أمانة المداية والتمكن في الكون بتسخير منه سبحانه. ومن حيث بجالاتا، يبين القرآن الكريم أن المعرفة تشمل عالم الشهادة والكون الطبيعي بأشيائه وأحداثه وظواهره، كما تشمل عالم الغيب الذي يتجاوز حس الإنسان في دنياه هذه، من ذات الله سبحانه ومخلوقاته في عالم الملائكة وعالم الجن، أو فيما وراء هذه الدنيا من آخره لها مخلوقاها من صراط وميزان وجنة ونار.

وهكذا فإن المعرفة إدراك بشري يتطلب السعي وبذل الجهد بالتفكير والتدبر وفي التفقه والفهم والتحقق، ولا يتعارض ذلك مع توفيق الله وتسديده لهذا السعي والكدح البشري وتفضله على بعض الناس بمزيد من الهداية. وهي علم يتفاوت في درجاته من شك وظن واعتقاد ويقين، وعمل بمقتضى العلم، وسلوك على أساسه، وهي شاملة لعالمي الغيب والشهادة والدنيا والآخرة، وشاملة لكل ميادين المعرفة البشرية وتعريفاتما المدرسية بما في ذلك العلوم الكونية الطبيعية، والعلوم الإنسانية والاجتماعية، والعلوم النقلية الشرعية.

وقد تمثل تكريم الله سبحانه لبني آدم وتفضيلهم على غيرهم من الخلق في خصائص عدة، أهمها العقل الذي به يتم الثفكير والفهم والإدراك، ومن ثمّ تحمّل الإنسان أمانة المسؤولية والاستخلاف في هذه الأرض. 
ولّما كان الفكر الإنساني والعمران البشري والإنجاز الحضاري كلها ترتبط ارتباطاً مباشراً باللغة؛ فقد علّم الله سبحانه الإنسان الأسماء كلّها من يوم خلقه.

واللّغة سواءً كانت رموزاً صوتية منطوقة أو رموزاً خطية مكتوبة، هي الأداة التي يفكر بها الإنسان، ويكوّن بها المعاني، ويتفاهم بها مع الآخرين، وتتناقلها الأجيال. ويتعذر على الإنسان أن يعرف أي معرفة من كتاب كتب بلغة لا يعرفها، أو من محاضرة بلغة لا يفهمها. بينما تثير الكلمات المكتوبة والأصوات المسموعة في ذهن القارئ أو السامع تلك الصور الذهنية المرتبطة بدلالاتها المعروفة في اللغة. وهكذا فإن اكتساب المعرفة الجلديدة يرتبط بالمعارف والمعلومات السابقة التي يعود أصلها القديم إلى تعليم الله لأبي البشر آدم عليه السلام، كما يعود أصلها المتجدد لدى كل فرد من بني آدم إلى ما يتعلمه الفرد في بيئته بالتلقين أولاً عن طريق الحواس والعقل:" والله أخرجكم من بطون أمهاتكم لا تعلمون شيئاً وجعل لكم السمع

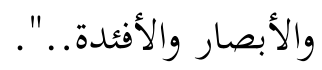

فالحواس هي أجهزة الاستقبال عند الإنسان التي تستقبل المثيرات الحسية سواء كانت الصور المرئية أو الأصوات المسموعة، فتتكون مهارات اللغة وتنشأ المدركات وتتراكم الخبرات، التي يرثها الإنسان من بيئته الاجتماعية والطبيعية- واللغة أداتما الأساسية- لتتفاعل مع قدراته التفكيرية الذاتية التي تأخذ بالاستقبال عن المؤثرات الوراثية، حيث ترتبط المعرفة الصحيحة بهذا الاستقبال وتتحدد في ضوئها مسؤولية الفرد الإنساني. لكن المعرفة الإنسانية تتجاوز ما يدركه العقل عن طريق المشاهدات الحسية المادية في عالم الشهادة ويبني منها القوانين والمبادئ والنظريات التي يصل بعضها إلى يقين، إلى التأمل والاستدلال في طوايا النفس الإنسانية وخطراتحا والتفكير في ما ينقل إليه من أخبار منقولة بالكلمة المقروءة والمسموعة، ويتوصل بذلك إلى قوانين ومبادئ وتصورات عما وراء الطبيعة والكون المادي وتتعلق بعالم الغيب، ويصل بعضها إلى اليقين أيضاً. فإعمال العقل بالتفكير بمنهج صحيح يمكن أن يقود إلى معرفة" علمية" مادية صحيحة عن طبيعة الأشياء والظواهر، وإلى معرفة "علمية" روحية صحيحة أيضاً عن قضايا الإيمان بالغيب. كما أن إعمال العقل بالتفكير الخطأ يمكن أن يقود إلى معرفة خطأ حول قضايا عالم الشهادة ومعرفة خطأ أيضاً حول عالم الغيب. 
وإذا كان العقل قادراً على تصحيح الخطأ في عالم الشهادة بمزيد من الاختبار والتجربة، فإن الوحي وحده قادر على ترشيد التفكير العقلي في قضايا عالم الغيب؛ لأن مهمة العقل تقف عند التصديق بمبدأ الغيب ووجود عالمه، ويتعذر استقصاء مضامين الغيب والتحقيق من كنهها بوسائله المعروفة في عالم الشهادة.

ويعدّ مبحث المعرفة في المنظور الإسلامي جزءاً من مبحث الوجود، لا ينفكُُ عنه ولا يفهم إلا في حدوده. فالوجود في المنظور الإسلامي يقوم على حقيقة أن الله سبحانه هو وحدهُ واجب الوجود، والموجودات هي مخلوقات لله سبحانه، لها وجود واقعي خارجي مستقل عن إدراك الإنسان وتصوراته الذهنية. وتقع هذه الموجودات ضمن فئتين: الوجود المادي والوجود الغيبي. أما التصور الذهني للإنسان فهو وجود من نوع آخر ينشأ عن فعل العقل الإنساني وخبرة الإنسان الحسية ووعيه المرتبط بالأشياء المادية أو باستدلاله

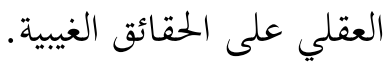

فالوجود المادي (المسوس) والوجود الغبيي (الروحي) مخلوقات لله سبحانه، متمايزة عن بعضها تمايزاً حاسماً، لا يلزم تفسير أحدهما بردّه إلى الآخر. وبهذا يتم حسم التراع الطويل بين الفلسفة الواقعية التي ترى أنه لا وجود إلاّ للواقع المحسوس، وأن الوجود النفسي والذهني الخاص بالإدراك هو بجرد انعكاس للوجود المادي المسسوس، والفلسفة المثالية التي ترى أن وجود الأشياء ليس إلا انعكاساً لوجودها الذهني وإدراكات الإنسان العقلية (الروحية) لها. والمهم أن هذا الحسم يتطلب الإيمان بوجود الله سبحانه، وبأنه الخالق للموجودات بإرادته واختياره، وأنه سبحانه كما يقول ابن تيمية: "الخالق للأمور الموجودة في الأعيان، والمعلّم للصور الذهنية المطابقة لما في الأذهان".

إن اتصاف الباحث بّ"المعرفة" و"المعرفية" يرتبط بالقدرة على التفكير والنظر المعري من خلال امتلاك مهارة نسميها "التحليل المعرفي". ونقصد بذلك القدرة على النظر الكلي الشمولي للمسألة موضوع البحث، ووضعها في الإطار العام الذي يضعها في موضعها المناسب من المسائل الأخرى، ويربط بينها وبين النظام المعرفي الذي تنتمي إليه، في ضوء الدائرة الحضارية الكبرى والمناخ الثقافي العام الذي ينتمي إليه الباحث. 
وحين يتعامل الباحث مع سؤال مطروح في الساحة الثقافية والإعلامية السائدة، فإنه لا بد من أن يعيد صياغة السؤال من منظور ربما يكون مغايراً للمنظور الأصلي الذي طرح فيه السؤال، وينظر في المفاهيم

$$
\text { والدلالات التي تحملها العبارة المكونة للسؤال. }
$$

وإذا كان المعنى القريب للتحليل يتضمن التقسيم إلى أجزاء، وبيان الوحدات التي يتكون منها الكل،

سواءً كان الكل شيئًا أو فكرة أو عملاً، فإن المقصود بالتحليل المعرفي في هذا المقام يتجاوز ذلك المعنى إلى البعد الفلسفي الذي يتطلب إدراكه قدراً من التفكير فيما يتجاوز السطح الظاهر من الشيء أو المعنى الظاهر من الفكرة. ولعلّ في التحليل الصحفي للأخبار، أو التحليل الأدبي للنص ما يشبه ذلك.

ففي كلتا الحالتين يتضمن التحليل ما يتجاوز القراءة الظاهرة للخبر أو النص إلى محاولة للقراءة الفاحصة التي تستهدف استحضار الإطار المرجعي للموضوع، واستحضار العناصر الأخرى له، وبناء تصور كلي، ورؤية شمولية للموقف.

ويتطلب التحليل المعرفي هذا الاعتبار وعياً فكرياً ومعالجة فلسفية، ولا يخلو هذا العمل من تفاوت في مستويات الجهد العقلي المطلوب؛ ففي الإجابة عن سؤال ما ربما يتطلب التحليل المعرفي للموقف أن يحاول المجيب أن يؤجل الإجابة المباشرة على السؤال، ليتأكد أن المطلوب من السؤال يتجاوز الإجابة إلى قضايا أخرى. ولذلك فقد ينصرف التفكير إلى بجمل الاعتبارات التي تحيط بظروف السائل والمسؤول والسؤال وعناصر الموقف التي ربما تكون ذات علاقة به، وعندها قد يلزم إعادة صياغة السؤال قبل الإجابة عنه، وقد يلزم تفكيك السؤال إلى أسئلة فرعية.

وهكذا فإن ثمة بعداً معرفياً عميقاً يكمن في أي خطاب أو أي سلوك، سواء قام به الإنسان بوعي أو بدون وعي، حتى ذلك الخطاب العفوي أو السلوك العادي. فالخطاب السياسي مثلاً الذي يتوجه نحو أسئلة وقضايا سياسية بحتة، والتحليل الاقتصادي الذي يعالج قضايا اقتصادية بكتة، يستندان في هاية التحليل إلى افتراضات نظرية أساسية ترتبط بالأسئلة الكلية الخاصة بالكون والحياة والإنسان والإله الخالق. 


\section{ويمكن التمييز في هذه الافتراضات بين المستويات الوجودية: Ontological والمعرفية}

\section{Methodological: والمنهجية Epistemological:}

وإذا كانت الافتراضات في المستوى المعريف نتيجة طبيعية مباشرة للإجابات التي تقدمها الرؤية الوجودية

الكلية فإفا تحدد بالتالي متطلبات التعامل المنهجي في مستوياته المختلفة.

ومن هنا تظهر أهمية تطوير التحليل المعرفي في العمل العلمي والثقافي حتى يتم إدراك العناصر

والخصائص المعرفية في هذا العمل.

ونحن المسلمين أشد حاجة اليوم إلى هذا التحليل المعرفي من الغربيين، لأن الغربيين ينطلقون في ما يكتبون من نظام معريف سائد مهيمن، وبالتالي فإن الأسئلة والقضايا التي يتعاملون معها تطرح من داخل السياق الحضاري. أما نحن فإننا نكاد نغرق في الإنتاج العملي والفكري والثقافي والفني والإعلامي الغربي دون الوعي الكافي بمنطلقات هذا الإنتاج أو آثاره.

وعندما كان واقع المسلمين من صنع أبناء المجتمع الإسلامي وصنع ثقافتهم وأعرافهم، كانت القضايا التي تثور والأسئلة التي تعرض جزءاً من السياق الحضاري السائد، ولذلك كانت الأمور تؤخذ بقدرها الظاهر وكانت الإجابات تقدم من داخل ذلك السياق. فالأسئلة كانت في الغالب تتطلب إجابات فقهية قانونية توضح حكم الشيء أو الفعل؛ والمنهج الفقهي منهج داخلي النظرة، يبحث في الواقع في ضوء النص، ويعتمد القياس، فهو منهج استنباطي استتاجي.

أما الآن فإن واقع المسلمين ليس من صنعتهم والثقافة السائدة ليست ثقافتهم، وكذلك فإن الأسئلة لابد أن تُعالج بطريقة مختلفة، وربما يكون المنهج الفقهي وحده ليس كافياً ولذلك لابد من منهج تحليلي نقدي توليدي يحلل الواقع، ويبين العناصر المعرفية الإسلامية وغير الإسلامية فيه، ويبدع البدائل، ويوازن بين خصائصها ومزاياها، ويعيد صياغة الأسئة وتكييفها حتى يكون بالإمكان تطوير الإجابات الإسلامية 
ولم تظهر أهمية توضيح النظام المعريف الإسلامي في السابق بصورة مباشرة لأنه لم تكن لدى علماء الأمة في السابق حاجة ظاهرة، لأفم كانوا يعملون ضمن نظام ثقافي حضاري معرفي سائد، تشبّعته نفوسهم، فالعالم الذي يتحدث أو يكتب مثله في ذلك مثل السامع أو القارئ دون أن يكون ثمة بجال لسوء الفهم. إنّ المعرفة في "إسلامية المعرفة" تشتمل على كل أنواع المعارف وتصنيفاها؛ فالمعارف "البشرية" المتعلقة بالقضايا النقلية الشرعية لم تقف عند جهود السلف ولا ينبغي لها ان تقف، وتبقى أبواب التجديد والاجتهاد البشري مفتوحة على مصاريعها متسلحة بما يلزم من أدوات، ومتحركة ضمن الهدي القرآني والبيان النبوي في فهم مقاصد الوحي في ضوء ما يفتح الله به على الإنسان من مغاليق، وما يحدث من مستجدات. والمعارف السائدة في ما يسمى بالعلوم الإنسانية والاجتماعية تواجه أزمات حقيقية في مناهجها ومعطياتا، يعرفها جيداً أهل الاختصاص، ولابد للعقل المسلم أن يتعامل معها على هذا الأساس فيعيد فهمها وتفسيرها في ضوء محدداتا الموضوعية وفي ضوء المحددات الذاتية للعلماء الذين أنتجوا وخلفياتم الحضارة والثقافية، وفي ضوء النظام المعري الإسلامي الذي يرشد إنجاز العقل البشري والخبرة البشرية بهداية الوحي الإلهي.

أما العلوم الطبيعية وما يحلق بها من علوم تطبيقية، فإن أمر التعامل معها يستوجب =إضافة إلى ما سبق - الوعي على أها وسيلة لهم هذا الكون المخلوق وتسخيره لصالح الإنسان المستخلف فيه، وأي مجال لتوظيف نتائج هذه العلوم في أبواب الضلال النفسي والفكري، أو الفساد الاجتماعي، أو العبث بمصالح الشعوب ومستقبل أبنائها، هو انحراف أخلاقي، يتطلب من العقل المسلم تصويبه.

المعرفة في "إسلامية المعرفة" تشتمل على هذه المجالات المعرفية جميعها، وخطابها موجه إلى أهل الاختصاص من علماء الأمة في كل مجال معريف: للتمكّن من التراث المعريف الإسلامي النقلي والعقلي وبحاوزه، وللتمكن من المعرفة الإنسانية المعاصرة وبحاوزها، ولإعمال العقل المسلم المعاصر في ذلكم كله بمنهج تحليلي نقدي، يتجاوز عقد التحلّي والتغنيّ بأبجاد ماضي الذات كما يتجاوز عقد الاستلاب لماضي الآخر أو حاضره.

المعرفة في "إسلامية المعرفة" عطاء إلهي يتحقق من امتلاك الرؤية الإسلامية الكونية، وإتقان المنهجية الإسلامية، وجزاء رباني على السعي الراغب والجهد الناصب، "واتقوا الله ويعلمكم الله"؛ ومع كل ذلك فهي 
ما كانت يوماً فاية المطاف، ولا لعالم فرد ولا لجيل من البشر، فثمّة علم يعلّمه الله لمن شاء متى شاء، وفق سنن ثابتة "ويعلّكم مالم تكونوا تعلمون" والحمد لله رب العالمين. 